\title{
Caspar Huberinus und die Reformation in Hohenlohe
}

\author{
von GunTHER Franz
}

\section{Archivforschung vor 50 Jahren}

Vor genau 50 Jahren, Anfang April 1967, begann für mich ein neuer Lebensabschnitt. Nach Beendigung des Theologiestudiums im Tübinger Stift bin ich mit einer mechanischen Schreibmaschine (die ich als 2. Preis in einem Preisausschreiben gewonnen hatte) im Hohenlohe-Zentralarchiv im Neuensteiner Schloss angekommen, um im Auftrag der Evangelischen Landeskirche in Württemberg eine Aktenausgabe über die Kirchenordnungen der Grafschaft Hohenlohe im 16. Jahrhundert zu erarbeiten und bei Professor Hermann Diem (19001975), dem Inhaber des Lehrstuhls für Kirchenordnung in Tübingen, ${ }^{1}$ über die Entstehung des Hohenlohischen Generalkonsistoriums zu promovieren. ${ }^{2}$ Bereits in dem ersten Gespräch hat der Fürstliche Archivrat Karl Schumm (1900-1976) ${ }^{3}$ mich ermuntert, später unbedingt über den hohenlohischen Reformator Caspar Huberinus (1500-1553) zu forschen. Von diesem im 16. Jahrhundert höchst verbreiteten Autor (es konnten später 20 verschiedene Schriften mit etwa 200 verschiedenen Ausgaben im 16. Jahrhundert ermittelt werden), war in Hohenlohe nur ein einziger Band Mancherley Form zu predigen 1565 in der Öhringer De-

1 Hermann Diem hatte 1957-1975 in Tübingen im Rahmen der Systematischen Theologie den einzigen Lehrstuhl für Kirchenordnung in einer Evangelisch-theologischen Fakultät inne, während das evangelische Kirchenrecht sonst in den Juristischen Fakultäten gelehrt wurde. Ihm war ein Anliegen, dass die Kirchenleitung nicht durch juristische Behörden (Konsistorien), sondern durch Kirchenvisitation und Predigt ausgeübt wurde. Hermann Diem: Kirchenvisitation als Kirchenleitung. In: Ders.: sine vi - sed verbo. Hg. von Uvo Andreas Wolf. München 1965 (Theologische Bücherei 25), S. 161-183.

2 Gunther Franz: Visitation und Konsistorium. Die Kirchenleitung der Grafschaft Hohenlohe im 16. Jahrhundert. Diss. maschinenschr. Tübingen, Evang.-theol. Fak. 1969; überarb. Druck: Ders.: Die Kirchenleitung in Hohenlohe in den Jahrzehnten nach der Reformation. Visitation, Konsistorium, Kirchenzucht und die Festigung des landesherrlichen Kirchenregiments 1556-1586 (Quellen und Forschungen zur württembergischen Kirchengeschichte 3). Stuttgart 1971; Ders.: Reformation und landesherrliches Kirchenregiment in Hohenlohe. In: WFr 58 (1974), S. 120-152. Dieser Aufsatz ist bei Christoph Bittel: Von der „Zeitschrift“ zum „Jahrbuch“. 100 Bände „Württembergisch Franken“. In: WFr 101 (2017), S. 317 versehentlich meinem Vater Günther Franz (1902-1992) zugeschrieben. Die evangelischen Kirchenordnungen des XVI. Jahrhunderts. Begründet von Emil Sehling. Bd. 15: Württemberg, I. Teil: Grafschaft Hohenlohe. Bearb. von Gunther Franz. Tübingen 1977.

3 Gunther Franz: Karl Schumm zum Gedächtnis. 22.12.1900-17.7.1976. In: BWKG 76 (1976), S. $234 \mathrm{ff}$. 
kanatsbibliothek zu finden, der inzwischen an die Landeskirchliche Zentralbibliothek in Stuttgart abgegeben worden ist. ${ }^{4}$

Im Neuensteiner Schloss warteten aber etwa sechs Kilometer Akten (man rechnet die Länge der Regalbretter zusammen), die nach dem Kriegsende aus den verschiedenen hohenlohischen Archiven zusammengeführt worden und überwiegend von einer Staubschicht bedeckt waren, auf die Erschließung. Daneben gab es noch die Schlossarchive in Weikersheim und Langenburg. Das Weikersheimer Archiv wurde 1967 vom Land Baden-Württemberg übernommen. 1971 wurde ein Vertrag zwischen dem Land und dem Haus Hohenlohe abgeschlossen, nach dem das Archivgut als Eigentum des Hauses Hohenlohe in Neuenstein verbleibt, aber staatlich verwaltet und betreut wird, seit 1975 als Außenstelle des Staatsarchivs Ludwigsburg. ${ }^{5}$ Die überreiche Fundgrube wurde von etwa 50 Doktoranden und Lehrern für Dissertationen und Zulassungsarbeiten genutzt, die für verschiedenste Aspekte die Grafschaft Hohenlohe als Beispiel bearbeiten konnten. Besonders der Rechtshistoriker Prof. Ferdinand Elsener (1912-1982) in Tübingen ${ }^{6}$ schickte gerne seine Doktoranden nach Neuenstein, weil sie dort die Quellenarbeit lernen konnten und von Herrn Schumm betreut wurden.

Für die Kirchengeschichte hat dies aber wenig gebracht ${ }^{7}$ und die Hohenlohische Kyrchen- und Reformations-Historie des Langenburger Hof- und Stadtpredigers Johann Christian Wibel (1711-1772), gedruckt in vier Bänden 1752-1755, war immer noch die beste Quelle. ${ }^{8}$ Die Fülle unbekannter Akten, die die Zeit und Lebensumstände im 16. Jahrhundert lebendig werden lassen, konnte den jungen Forscher geradezu in einen Rausch versetzen. Durch das reiche Archivmaterial wurde es möglich, die eigenständige Entwicklung eines kleineren Territoriums und seiner Ordnungen in der zweiten Hälfte des 16. Jahrhunderts umfassend darzustellen. Nicht nur die Vorgeschichte, sondern auch die Durchführung der Ordnungen und Gesetze konnte dokumentiert werden. ${ }^{9}$

4 Aus einer bibliothekarischen Zulassungsarbeit 1970-1971 entstand: Gunther Franz: Huberinus - Rhegius - Holbein; der Druck von Huberinus: Mancherley Form zu predigen. Nürnberg 1557 in: Gunther Franz: Huberinus - Rhegius - Holbein. Bibliographische und druckgeschichtliche Untersuchung der verbreitetsten Trost- und Erbauungsschriften des 16. Jahrhunderts (Bibliotheca humanistica et reformatorica 7). Nieuwkoop 1973, S. 195, Nr. 22.6 und Sehling/Franz (wie Anm. 2), S. 31-44; VD16 (Verzeichnis der im deutschsprachigen Raum erschienenen Drucke des 16. Jahrhunderts) H 5628; Landeskirchliche Zentralbibliothek Stuttgart Oktav/782.

5 Gerhard Taddey: Das Hohenlohe-Zentralarchiv in Neuenstein. In: Beiträge zur Landeskunde. Beilage im Staatsanzeiger für Baden-Württemberg 1972, Nr. 6, S. 8-13.

6 Seit 1959 Professor für deutsche Rechtsgeschichte und Kirchenrecht in Tübingen.

7 Kurt Futter: Die kirchlichen Zustände in der Grafschaft Hohenlohe im Zeitalter nach der Reformation. In: BWKG 53 (1953), S. 64-82; Fritz Ulshöfer: Das Kirchenregiment in der Grafschaft Hohenlohe bis zum Jahre 1806. In: BWKG 64 (1964), S. 104-113; Kuno Ulshöfer: Die Geschichte des Klosters Schäftersheim. Tübingen, Phil. Diss. 1962.

8 Johann Christian Wibel: Hohenlohische Kyrchen- und Reformations-Historie, Aus bewährten Urkunden und Schriften verfasset. Band [1]-4. Onolzbach (=Ansbach) 1752-[1754]. Elektronische Ressource UB Tübingen.

9 Sehling/Franz (wie Anm. 2), S. 19 ff. (Zum Forschungsstand und dem vorgelegten Ordnungswerk). 


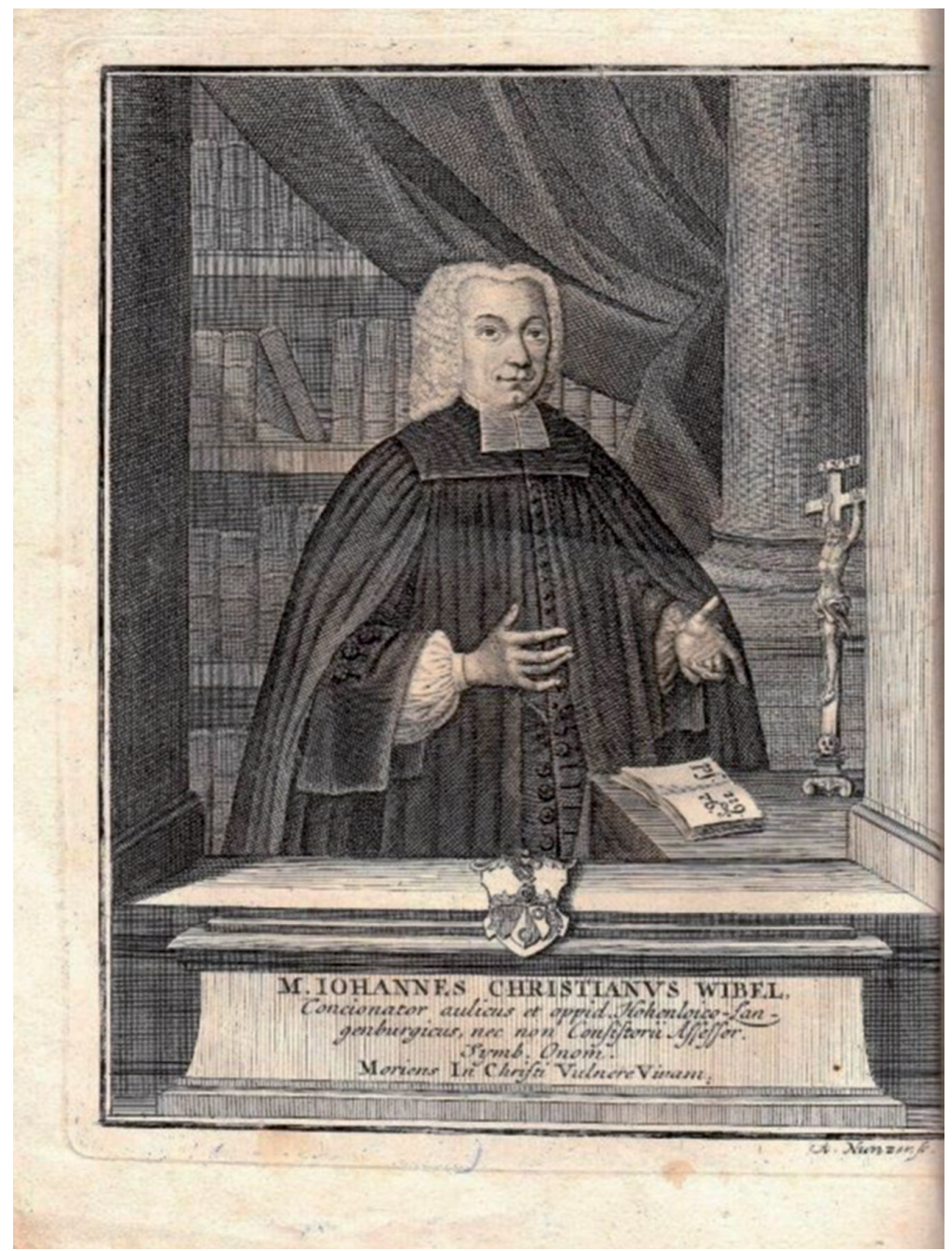

Abb. 1: Johann Christian Wibel, Kupferstich von A. Nunzer. Die Anfangsbuchstaben des Namens MICW ergeben das Symbolum Onomasticum: Sterbend lebe ich durch die Wunde Christi. Frontispiz zu Wibels Hohenlohische Kyrchenund Reformations-Historie, Bd. 1, 1752. Privatbesitz.

Im November 1967 unternahm der Historische Verein für Württembergisch Franken einen Besuch des Neuensteiner Archivs und Karl Schumm überließ mir, die Funde zur Kirchengeschichte vorzustellen. Da war es ein Ansporn, dass der Vorsitzende Gerd (Gerhard) Wunder (1908-1988) ${ }^{10}$ am 30. November 1967 im Haller

10 Dieter Wunder: Gerd Wunder. In: WFr 58 (1974), S. 7-13. 
Tagblatt einen Bericht veröffentlichte: „Die hohenlohische Reformationsgeschichte verlief ganz anders". Er meinte: anders, als man bis jetzt wusste. Man kann die Überschrift aber auch deuten: Die Einführung der Reformation verlief in Hohenlohe anders als in vergleichbaren deutschen Territorien, nämlich in vier Stufen.

\section{Wann wurde die Reformation in Hohenlohe durchgeführt?}

Die Frage, in welchem Jahr die Reformation in der Grafschaft Hohenlohe eingeführt worden ist, 1544 oder 1556, war im 16. und 17. Jahrhundert von entscheidender Bedeutung für den Bestand der Grafschaft. Nach Beginn der Gegenreformation in Franken übersandte Bischof Julius Echter von Mespelbrunn in Würzburg (reg. 1573-1617) 1575 Beschwerdepunkte, Hohenlohe habe widerrechtlich das Stift Öhringen, das Kloster Schäftersheim und 36 Pfarren und Benefizien der Jurisdiktion des Würzburger Bischofs entzogen. 1589 wurde Hohenlohe vor das Reichskammergericht nach Speyer zitiert. Als im Dreißigjährigen Krieg die kaiserliche Seite Überhand hatte, sollten durch das Restitutionsedikt, die Verordnung von Kaiser Ferdinand II. vom 6. März 1629, alle Klöster und Stifte zurückgegeben werden, die erst nach dem Passauer Vertrag von 1552 reformiert worden waren. ${ }^{11}$ Von Hohenlohe wurde eine Denkschrift erstellt, deren 1. Teil 403 Seiten umfasste. (Der 2. Teil war anscheinend nicht mehr notwendig.) Acta Inn Sachen Fürstlich Würtzburgischen Anwaldts und deß Praemonstratenser Ordens Gegen Die Samptliche Herrn Graven von Hohenloe. ${ }^{12}$ Dass es Ernst war, zeigt das erste Reskript vom 20. September 1629, in dem es heißt: Wann uns dann unter anderm glaublich vorgebracht worden, welcher gestalten das Stifft Oeringaw, neben dessen Pfarr, Hospital unnd newen Praebenden zu jetztbemeltem Oeringaw, wie nicht weniger daß Closter Scheffterheim sampt der Pfarr Schefftersheimb und dessen Frümess in der Würzburger Diözese von der Grafschaft Hohenlohe dem klaren Buchstaben des Augsburger Religionsfriedens von 1555 entgegen erst nach dem Passauer Vertrag von 1552 unbefugter Weise eingezogen worden ist. Dagegen wurde von der hohenlohischen Seite angemerkt, dass ein glaublichs Vorbringen [...] wider ein 80 oder fast 90 Jährig ruhige possession eines ReichStandts angeführt wurde. Das kaiserliche Edikt setze besondere qualitates und Erfordernisse voraus, die in jedem Fall exactissi-

11 Michael Frisch: Das Restitutionsedikt Kaiser Ferdinands II. vom 6. März 1629 (Jus Ecclesiasticum 44). Tübingen 1993; der Text des Edikts S. 183-194.

12 Acta Inn Sachen Fürstlich Würtzburgischen Anwaldts und deß Praemonstratenser Ordens Gegen Die Samptliche Herrn Graven von Hohenloe etc. Ihrer Gräflichen Gnaden angesprochener Geistlichen Güter halb zu Oeringaw und Schefftersheimb Vor denen in dem Fränckischen Reichs-Crayß verordneten Herrn Commissariis, in Annis 1629 \& 1630 verhandelt. O. O. (Druck Simon Halbmaier in Nürnberg?) 1630; VD 17 (Verzeichnis der im deutschsprachigen Raum erschienen Drucke des 17. Jahrhunderts) 12:000056Y. 


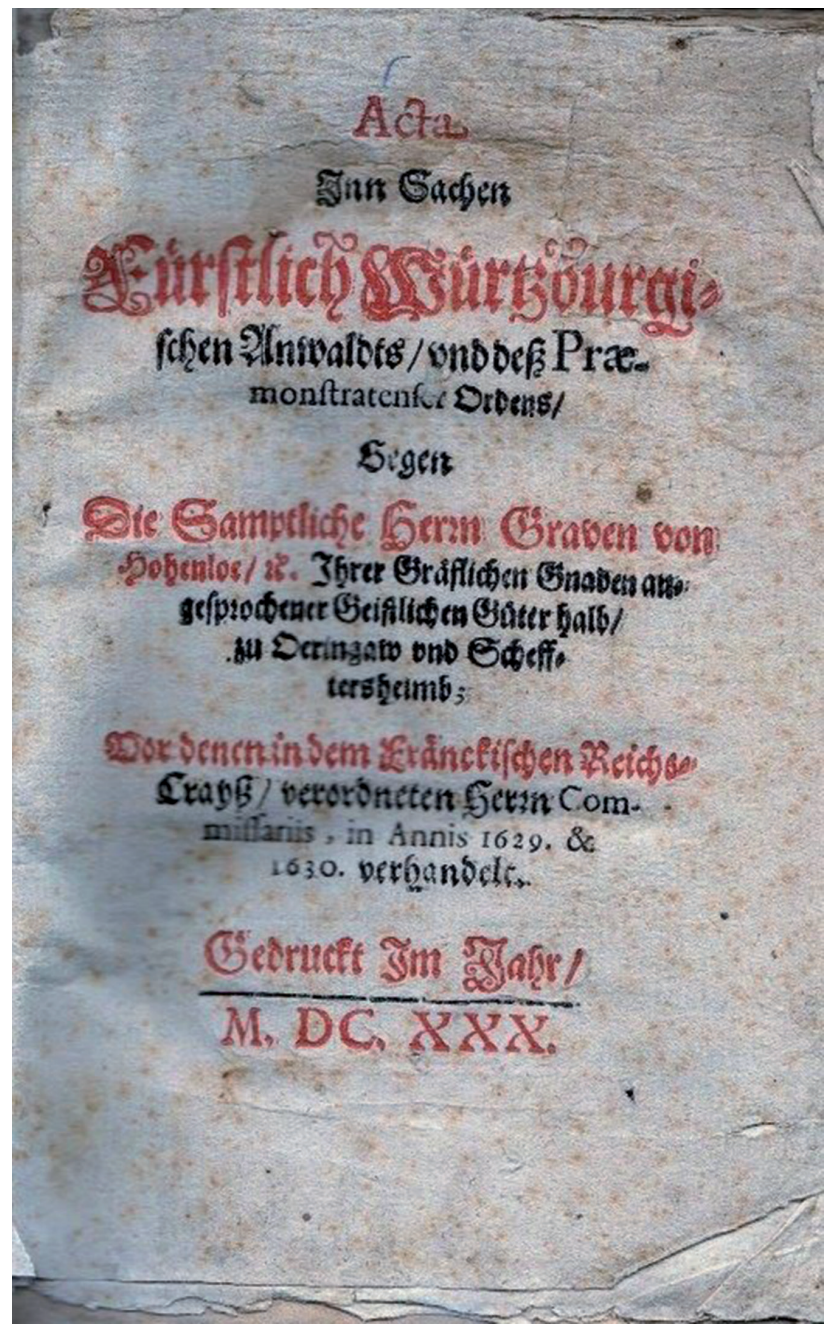

Abb. 2: Titelblatt Acta Inn Sachen Fürstlich Würtzburgischen Anwaldts [...]. Privatbesitz.

me zu erforschen seien. ${ }^{13}$ Das Kloster Schäftersheim wurde wieder von Prämonstratenserinnen bewohnt; die Rückgabe des Öhringer Stifts mit seinen reichen Besitzungen wurde von der Stadt verhindert. Als die Kommissare am 20. März 1530 mit fünf Kutschen und 15 Pferden vor Öhringen erschienen, fanden sie die Brücke aufgezogen und das Stadttor verschlossen. ${ }^{14}$

13 Ebd., S. 3 f.

14 Adolf Fischer: Das Restitutionsedikt von 1629 und seine Folgen in Hohenlohe. In: Württember- 
Als Anhang zu den Acta in Sachen [...] wurden die Akten der Berufung von Caspar Huberinus als Öhringer Stiftsprediger 1544 abgedruckt, die sich dann auch bei Wibel finden und teilweise in der 1977 gedruckten Ausgabe der Evangelischen Kirchenordnungen von Hohenlohe. ${ }^{15} 1544$ lag deutlich vor dem Stichjahr 1552, die endgültige Reformation 1556 aber erst nach dem Augsburger Religionsfrieden von 1555, in dem den Fürsten vom Reich zugestanden wurde, über die Religion ihrer Untertanen zu bestimmen, sinngemäß nach dem Motto cuius regio, ejus religio, das sich aber weder im Religionsfrieden noch im Westfälischen Frieden findet, sondern von dem Juristen Joachim Stephani (15441623 ) geprägt wurde. ${ }^{16}$

\section{Der Beginn der Reformation in der Herrschaft Weikersheim und in Öhringen ${ }^{17}$}

Die Brüder Albrecht III. (reg. 1504-1551) und Georg I. (reg. 1503-1551), Grafen von Hohenlohe, nahmen zunächst eine abwartende Haltung ein und wurden wahrscheinlich durch den Bauernkrieg 1525, in dem sie sich am Grünbühl unterwerfen mussten, zu einer aktiv antireformatorischen Haltung gebracht. Matthäus Chyträus (Kochhaff, 1495-1559), seit 1525 Pfarrer in Ingelfingen, wurde 1530 vom Beamten mit dem Degen auf der Kanzel bedroht, als er gegen die befohlene Wiedereinführung der Messe predigte. ${ }^{18}$ Die Wirksamkeit von Johannes Brenz (1499-1570) in Schwäbisch Hall (1522-1548) und die Reformation der Reichsstadt 1526/27 hatten keinen größeren Einfluss auf die Grafschaft. Das 1525 veröffentlichte Syngramma Suevicum gegen die Abendmahlslehre von Johannes Oecolampad (1482-1531) ist von Theologen aus dem schwäbisch-fränkischen Grenzraum verfasst; beteiligt war Wolfgang Taurus (Stier), 1524-1532 Pfarrer in Orendelsall. ${ }^{19} 1534$ wurde die Forderung des - zum Teil hällischen - Pfarrvolks von Ruppertshofen nach Abendmahl unter beiderlei Gestalt abgelehnt. ${ }^{20}$

gische Jahrbücher für vaterländische Geschichte, Geographie, Statistik und Topographie 1861, S. 81-108; Ders.: Geschichte des Hauses Hohenlohe. Teil II, 1, o.O. 1868, S. 56-58.

15 Acta (wie Anm. 12), S. 124-191, besonders S. 150-169; Wibel (wie Anm. 8), 3, Corpus Diplomaticus S. 306-331; Sehling/Franz (wie Anm. 2), S. 23-27.

16 Martin Heckel: Religionsbann und landesherrliches Kirchenregiment. In: Ders.: Gesammelte Schriften, Bd. 3. Tübingen 1997, S. 262-293.

17 Franz: Reformation und landesherrliches Kirchenregiment (wie Anm. 2); Ders.: Reformation im Tauberland. Gebiet des Kirchenbezirks Weikersheim mit Mergentheim und Creglingen. In: BWKG 1988, S. 78-110; Ders.: Die Reformation in Öhringen und die Aufhebung des Stifts (15441556). In: Öhringen Stadt und Stift. Red.: Gerhard Taddey u. a. Öhringen 1988, S. 103-116.

18 Otto Haug unter Mitarbeit von Max-Adolf Cramer und Marlene Holtzmann: Pfarrerbuch Württembergisch-Franken, T. 2: Die Kirchen- und Schuldiener (Baden-Württembergisches Pfarrerbuch II,2). Stuttgart 1981, Nr. 1297.

19 Johannes Brenz: Frühschriften T. 1, hg. Martin Brecht, Gerhard Schäfer, Frieda Wolf. Tübingen 1970; Haug/Cramer/Holtzmann (wie Anm. 18), Nr. 2687.

20 Wibel (wie Anm. 8), 3, Corpus Diplomaticus S. 301. 
Schwäbisch Hall suchte innerhalb der „Landwehr“ als Schutz- und Rechtsgrenze ein geschlossenes Territorium zu bilden. Auf dem Untermünkheimer Tag mussten die Grafen von Hohenlohe am 1. Februar 1543 unter Vermittlung Landgraf Philipps von Hessen zustimmen, dass die Pfarreien Jungholzhausen, Untermünkheim, Gailenkirchen, Braunsbach und die Kaplanei Enslingen mit evangelischen Pfarrern, die entsprechend der Augsburgischen Konfession examiniert waren, besetzt würden. Hohenlohe behielt aber das Präsentationsrecht für die Pfarrer. ${ }^{21}$ Später wurde die Rechtslage auch im umgekehrten Fall angewandt: Hollenbach und Adolzhausen südlich von Weikersheim gehörten zu Hohenlohe; die Patronate hatte aber der Deutsche Orden in Mergentheim. Es wurde 1578 eine Art Staatsvertrag geschlossen, dass nur Kandidaten eingesetzt werden durften, die vorher eine Prüfung beim Konsistorium in Öhringen bestanden hatten. ${ }^{22}$ Graf Wolfgang I. (reg. 1532-1545) war der erste Graf von Hohenlohe, der in seiner Teilherrschaft Weikersheim mit Schillingsfürst 1544/45 evangelische Pfarrer einsetzte. Nach Johann Balthasar Fleiners Hohenlohischer Chronik soll er schon 1535 die erste Kirchenreformation vorgenommen haben. ${ }^{23}$ Die Frühmesse in Schäftersheim, deren Kollatur (Pfarrbesetzungsrecht) dem Grafen zustand, hat er 1541 mit Georg Gscheid († 1544) besetzt. Am 8. Januar 1545 schrieb Graf Wolfgang an den Bischof von Würzburg, er habe evangelische Pfarrer in Nassau und Schäftersheim eingesetzt, da das Stift Neumünster in Würzburg als Patronatsherr untätig gewesen sei: Wahr ists aber, daß ich mit müh Pfarrverseher gen Nassau unnd Schefftersheim gebracht, der ehrn hette ich jnen wol gonnen mögen. ${ }^{24}$ Graf Wolfgang hat also in Luthers Sinn als Notbischof gehandelt. Auch nach Weikersheim und Elpersheim holte er evangelische Pfarrer.

Öhringen mit dem reichen Chorherrnstift war als Hauptstadt der Grafschaft Hohenlohe im gemeinsamen Besitz aller Grafen; hier hatten die Bürger ein stärkeres städtisches Bewusstsein. Nachdem die 1506 errichtete Predigerstelle (Stiftsprädikatur) in Öhringen ${ }^{25}$ unbesetzt war und von den Stiftsherren keine Seelsorge geübt wurde, richteten am 8. Januar 1544 Schultheiß, Bürgermeister und Rat eine Bittschrift an die beiden Grafen Albrecht und Georg wegen eines evangelischen Predigers und der Erlaubnis, dass das Abendmahl nach evangelischer Weise unter beiderlei Gestalt gereicht werden dürfe. In einem Umkreis von 40 Meilen sei keine Gemeinde kirchlich so schlecht versorgt wie Öhringen. Alle Bürger hätten

21 Kuno Ulshöfer: Der Untermünkheimer Tag und Abschied. In: WFr 50 (NF 40, 1966), S. 280 292; Politisches Archiv des Landgrafen Philipp d. Großmütigen von Hessen. Hg. Friedrich Küch. Bd. 2. Leipzig 1910 (Publikationen a. d. K. Preuß. Staatsarchiven 85), S. 550.

22 Sehling/Franz (wie Anm. 2), S. 221-225.

23 Johann Balthasar Fleiner: Hohenlohische Chronik. Württ. Landesbibliothek Stuttgart, Hist. Hs. Fol. 691, B1. 316.

24 Wibel (wie Anm. 8), 1, S. 477; nach Haug/Cramer/Holtzmann (wie Anm. 18), Nr. 814, ist Gscheid [1545] gestorben. Es war aber bereits im Vorjahr 1544, Acta (wie Anm. 12), S. 228-242, das Zitat S. 239; Franz, Reformation im Tauberland (wie Anm. 17), S. 92.

25 Matthias Simon: Die Stiftspredigerstelle zu Öhringen als Movendelpfründe. In: Würzburger Diözesangeschichtsblätter 26 (1964), S. 186-191. 
gegenüber den Pfarrern ob ihrer gottlosen lehr und ärgerlichen leben ein grewel und abschewen. Das gemeine volk müsse ohne alle geistliche unterweisung und sacrament verscheiden. ${ }^{26}$ Hinter der Initiative stand der (seit 1530) hohenlohische Rat D. Ägidius (Gilg) Stem(b)ler, der in Tübingen und Basel studiert hatte und seit langem evangelisch gesinnt war. Er wusste, dass die Grafen noch nicht zur Reformation bereit waren und eine allgemeine Regelung im Reich abwarten wollten. Stemler war bereits ein Jahr zuvor auf den lutherischen Theologen Caspar Huberinus in Augsburg aufmerksam geworden. Mittelsmann war der aus Öhringen stammende Buchhändler und Verleger Wolf Präunlein (Bräunlein, vor 1490-1558), der Schwiegersohn und Nachfolger des bedeutenden Buchhändlers Johannes Rynmann aus Öhringen (1460-1522). ${ }^{27}$

\section{Huberinus - „Luthers Mann in Augsburg“6}

Kaspar (Caspar) Huber ${ }^{28}$ wurde am 21. Dezember 1500 in Stotzard (heute Markt Aindling, Landkreis Aichach-Friedberg) in Bayerisch-Schwaben geboren. ${ }^{29}$ Dort erinnert eine Caspar-Huberinus-Straße an ihn, während es in Öhringen einen Huberinus-Platz gibt. Es wurde auch ein Geburtsort „Wilspach“ genannt, was Ober- oder Unterwittelsbach in der Nachbarschaft sein muss (der Stammsitz der Wittelsbacher gehört heute zu Aichach). Caspar veröffentlichte seine Schriften unter dem später ausschließlich geführten latinisierten Namen Huberinus, selten auch als Hůber oder Hueber. Vielleicht war er in jungen Jahren ein Mönch. Ein sacrificulus (Inhaber einer Altarpfründe) kann er nicht gewesen sein, da er keine Priesterweihe besaß. Deswegen durfte Huberinus in der Zeit der teilweisen Rekatholisierung Deutschlands im Augsburger Interim 1551/1552 keine Sakramente spenden.

26 HZA Neuenstein, PA 93, 3, 6; Acta (wie Anm. 12), S. 151.

27 Gunther Franz: Johannes Rynmann (1460-1522), Wolf Präunlein (Bräunlein) (vor 1490-1558). In: Öhringen. Stadt und Stift (wie Anm. 17), S. 530 ff. Die Grabplatte von Hans Rynmann befindet sich im Kreuzgang der Öhringer Stiftskirche; das Grabmal des Wolfgang Präunl(e)in und seiner Frau Agatha geb. Rynmann in der Gruft der Kirche ist nicht erhalten; Die Inschriften des Hohenlohekreises. Gesammelt und bearb. von Harald Drös. Teil 1.2. (Die deutschen Inschriften: Heidelberger Reihe 16 = Die deutschen Inschriften 73). Wiesbaden 2008. Auch: Deutsche Inschriften online. DI 73, Hohenlohekreis, in: www.inschriften.net, urn:nbn:de:0238-di073h016k, Nr. 214, Abb. 126 und Nr. $363 \uparrow$.

28 Franz: Huberinus (wie Anm. 4); Ders.: Kaspar Huberinus. Der Öhringer Reformator als international bekannter Erfolgsautor. In: WFr 59 (1975), S. 26-51; Abdruck mit Textanhang in: Reformation in Hohenlohe. 400 Jahre Hohenlohische Kirchenordnung 1578-1978. Stuttgart 1979, S. 36-50; Works by Caspar Huberinus (1500-1553). Collection: 47 titles on 156 positive silverhalide microfiches. Ed. Gunther Franz. Zug 1986; Ders.: Kaspar Huberinus und die Reformation in Hohenlohe. In: Reformationsgeschichte Württembergs in Porträts. Hg. Siegfried Hermle. Holzgerlingen 1999, S. 345-362, auch in: Württembergische Kirchengeschichte online: wkgo.de/cms/article/print/272. 291535 ist ein Revers an Bürgermeister und Rat der Stadt Augsburg wegen Bestallung zum Prädikanten und Diakon unterzeichnet: Caspar Hueber von Stotzhart. StadtA Augsburg (Autographen). 


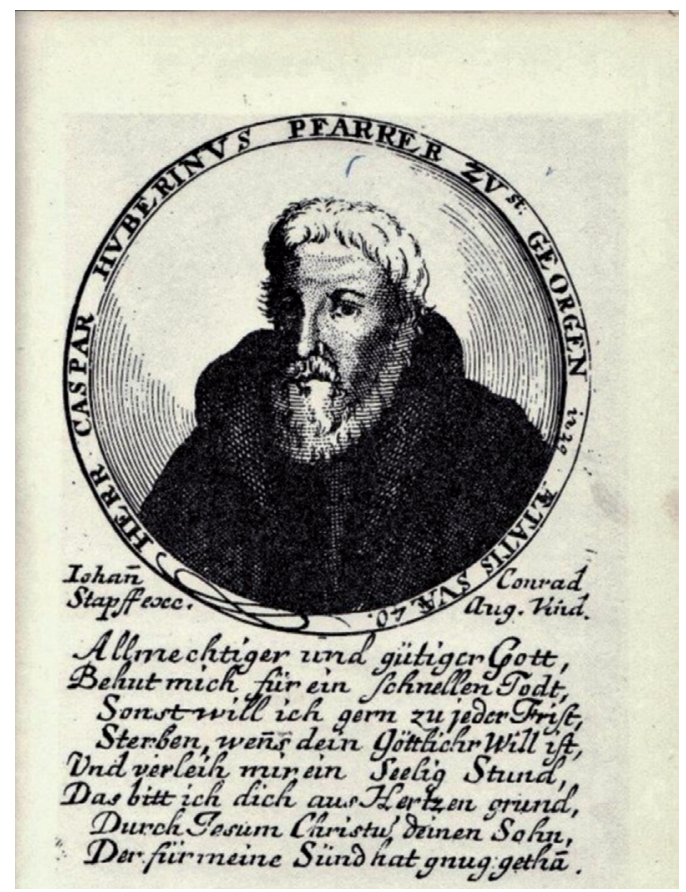

Abb. 3: Bildnis von Caspar Huberinus 1539. Nachstich des 18. Jahrhunderts (Johann Conrad Stapff, gest. 1762). Aus einer Folge der Staats- und Stadtbibliothek Augsburg (Graph. 20/238b).

1522 wurde Huber in Wittenberg immatrikuliert, wo er ein treuer Schüler Luthers wurde und dessen persönliche Bekanntschaft machte. $1525 \mathrm{kam}$ er in die Reichsstadt Augsburg, wo er im folgenden Jahr die Benediktinerin Afra Seld heiratete. Dies geschah nach dem Vorbild Luthers, dessen Eheschließung mit der ehemaligen Nonne Katharina von Bora (1499-1552) 1525 großes Aufsehen erregt hatte. Augsburg war ein Zentrum der Renaissancekunst in Deutschland und Afras Vater Jörg II. Seld (um 1454-1527) ein überragender Goldschmiedemeister. Afras Bruder Georg Sigismund Seld (1516-1565) wurde Reichshofrat und Reichsvizekanzler. ${ }^{30}$

In Augsburg gab es drei konfessionelle Parteien: Katholiken, Anhänger Luthers und Zwinglis. ${ }^{31} \mathrm{Ab} 1524$ tobte der Abendmahlsstreit zwischen Anhängern Zwinglis und Luthers, die als Minderheit völlig isoliert waren. Huberinus erhielt

30 Norbert Lieb: Die Augsburger Familie Seld. In: Lebensbilder aus dem Bayerischen Schwaben 6 (1986), S. 38-87.

31 Friedrich Roth: Augsburgs Reformationsgeschichte 12. München 1901 (Register); Rolf Kießling: Augsburg in der Reformationszeit. In: Augsburger Stadtlexikon. Augsburg 2013, www.stadtlexikon-augsburg.de. 
kein Kirchenamt, wurde aber vom Rat der Stadt zur Berner Disputation im Januar 1528 abgeordnet. Es waren Vertreter der eidgenössischen Stände sowie zahlreicher süddeutscher Städte eingeladen worden. In den zehn Thesen ging es um die alleinige Herrschaft Christi in der Kirche, das reformatorische Schriftprinzip, die Rechtfertigung allein durch Christus, das Abendmahl und die Frage der Bilder in den Kirchen. ${ }^{32}$ In den Folgejahren bis 1532 wurde die Reformation im zwinglischen Sinne in dem wichtigen Kanton Bern eingeführt.

1529 hat der Drucker Philipp Ulhart in Augsburg von Huberinus die Schrift Vom Zorn und der Güte Gottes veröffentlicht. ${ }^{33}$ In gewandter dramatischer Einkleidung treten zwei Personen auf. Mittels einer Auslegung der zehn Gebote wird Christianus der Zorn Gottes über die Sünder vor Augen gestellt. Aber Theodidactus tröstet den angefochtenen und vom Satan versuchten Christen in mehreren Anläufen. Beigefügt ist die Trostschrift Wie man den Sterbenden trösten und ihm zusprechen solle. Als Nachfolgerin der spätmittelalterlichen Sterbetrostschriften kam sie einem verbreiteten Bedürfnis entgegen. Ab 1532 wurde Huberinus von Hans Hanold ( $†$ 1540), einem reichen Augsburger Bürger und Stütze der lutherischen Partei, aus einer Stiftung unterhalten. Beide standen mit Luther in Briefwechsel und beschwerten sich über die Gegner in Augsburg, die nicht mit Verleumdungen sparten und giftige Äußerungen über Luther machten. ${ }^{34}$ Seine Schrift Von bösen falschen Zungen hat Huberinus 1531 den Brüdern Hans und Peter Hanold gewidmet. Luther veranlasste 1534 einen Nachdruck der Schrift Vom Zorn und der Güte Gottes in Wittenberg und empfahl sie durch ein Vorwort. Entsprechend dem Bibelwort Matthäus 7, $24 \mathrm{f}$. werde das Buch, wie ein Haus auf den Fels gebaut, sicher bleiben..$^{35}$ Luther förderte gerne in dieser Art Schriften seiner Anhänger. Von 1535 bis 1570 gab es 15 niederdeutsche Ausgaben Vam Thorn und der Güdicheit Gades, die in Magdeburg, Lemgo und Hamburg gedruckt wurden. Niederdeutsch war im 16. Jahrhundert eine Schriftsprache. 1543 und 1548 folgten dänische Übersetzungen und 1579 eine isländische Übersetzung, gedruckt im kleinen Bischofssitz Hólar in Nordisland, das als eines der ersten isländischen Bücher kulturgeschichtliche Bedeutung hat. Die bei-

32 Irene Backus: Das Prinzip ,sola scriptura“ und die Kirchenväter in den Disputationen von Baden (1526) und Bern (1528). Zürich 1997; Gottfried Wilhelm Locher: Die Berner Disputation 1528. Charakter, Verlauf, Bedeutung und theologischer Gehalt. In: Zwingliana 14 (1978), S. 542-564; http://www.zwingliana.ch/index.php/zwa/article/download/895/805.

33 Franz, Huberinus (wie Anm. 4), S. 11-16, 69-87; die Ausgabe Augsburg 1532 (ebd., Nr. 1.3) = VD 16 (wie Anm. 4) H 5466 mit Volltext nach dem Exemplar der Österreichischen Nationalbibliothek Wien.

34 Schreiben von Luther an Huberinus vom 3.1.1532. In: Luther, Werke - Briefe Bd. 6, Nr. 1894; Schreiben von Huberinus an Luther vom 20.6.1533, Nr. 2030; Schreiben von Luther an Hans Hanold vom 21.6.1533 betreffend die Anfrage von Huberinus, Nr. 2039. Späterer Brief von Luther an Huberinus vom 5.10.1535, In: Briefe Bd. 7, Nr. 2257 und von Huberinus an Luther vom 23.10.1536, Nr. 3092.

35 Martin Luther: Vorrede zu Caspar Huberinus, Vom Zorn und der Güte Gottes. In: D. Martin Luthers Werke. Kritische Gesamtausgabe. Bd. 38, S. 315-325; Bd. 60. Weimar 1980, S. 105-113 (Nachtrag von Gunther Franz). 
gefügte Trostschrift Wie man den Sterbenden trösten und ihm zusprechen solle hat noch ihre eigene Geschichte. Sie wurde ab 1531 mehrfach in Antwerpen in den spanischen Niederlanden gedruckt und als häretische Schrift verfolgt und (ebenfalls ohne Nennung des Autors) den berühmten Totentanzbildern von Hans Holbein d. J. beigefügt. Mit etwa 125 Ausgaben in fast einem Dutzend Sprachen gehört die kleine Schrift zu den verbreitetsten Texten des 16. Jahrhunderts. ${ }^{36}$ Nach dem Tod Zwinglis in der Schlacht von Kappel 1531 erkannte der Rat der Stadt Augsburg, dass man gegenüber der kaiserlich-katholischen Partei Verbündete brauche und sich mit Martin Luther aussöhnen müsse, um den Schutz des Schmalkaldischen Bundes zu erhalten. Da freute man sich, mit Huberinus einen Verbindungsmann zu haben. Er erhielt 1535 ein Kirchenamt als Diaconus (2. Pfarrer) und 1542 als Pfarrer. Huberinus nahm neben den reformierten Theologen Wolfgang Musculus (1497-1563) und Bonifacius Wolfhart (um 1490-1543) mit dem Augsburger Stadtarzt Gereon Sailer (um 1500-1562) ${ }^{37}$ an den Verhandlungen um die Wittenberger Konkordie teil. Die Formula Concordiae Lutheri et Buceri ist eine wesentlich von Philipp Melanchthon geprägte Übereinkunft, um die Differenzen zwischen den Wittenberger Theologen und den Vertretern der Schweizer und „oberdeutschen“ Reformation im Verständnis des Abendmahls zu überbrücken. Weitere Themen der Verhandlungen vom 21.-28. Mai 1536 in Wittenberg waren die Taufe, Absolution, Schule und Obrigkeit. ${ }^{38}$

Aus Predigten für die Jugend gestaltete Huberinus eine Gesamtdarstellung der christlichen Lehre, die die Übereinstimmung mit der lutherischen Lehre in Norddeutschland bezeugen sollte. Von dem Buch Von der wahren Erkenntnis Gottes sind in den Jahren 1537-1570 15 verschiedene hochdeutsche Auflagen und sechs niederdeutsche nachweisbar. ${ }^{39}$ In der Vorrede unterschied Huberinus menschliche und himmlische Weisheit. Die größte Weisheit dieser Welt ist vor Gott die höchste Torheit (1. Kor. 1, 25). Dem entspricht das Motto auf dem beigefügten Titelholzschnitt Summa sapientia stultitia, das sich auch auf dem Epitaph in der Öhringer Friedhofskirche findet. ${ }^{40}$ Aus dem Jugendunterricht erwuchs der Catechismus von 1543. Ein Auszug Der klaine Catechismus. Mit vil schönen sprüchen hailiger schrifft gegründet, Für die jugent zůgebrauchen hat eine auf den

36 Franz: Huberinus (wie Anm. 4), S. 69-144.

37 Gereon Sailer war 1530 bis zu seinem Tod 1562 Stadtarzt in Augsburg. Er führte einen Briefwechsel mit Landgraf Philipp von Hessen. Ralph Andersson: Aichacher als Makler zwischen Luther, Zwingli und dem Interim. Gereon Sailer und Caspar Huberinus auf ihrem Weg durch die Reformation. In: Aichacher Heimatblatt 53 (2005), S. 5-11; Augsburger Stadtlexikon (wie Anm. 31).

38 Thomas Kaufmann: Wittenberger Konkordie. In: Theologische Realenzyklopädie 36. Berlin, New York 2004, S. 243-251.

39 Franz: Huberinus (wie Anm. 4), S. 54, 164-169; die Ausgabe Wittenberg 1537 (Franz, Nr. 14.2)

=VD 16 (wie Anm. 4), H 5416 mit Volltext nach dem Exemplar der Universitätsbibliothek Jena.

40 Gunther Franz: Grabschrift und Wappen des Theologen Caspar Huberinus in seinen Schriften.

In: Gutenberg-Jahrbuch 1971, S. 138-143. 


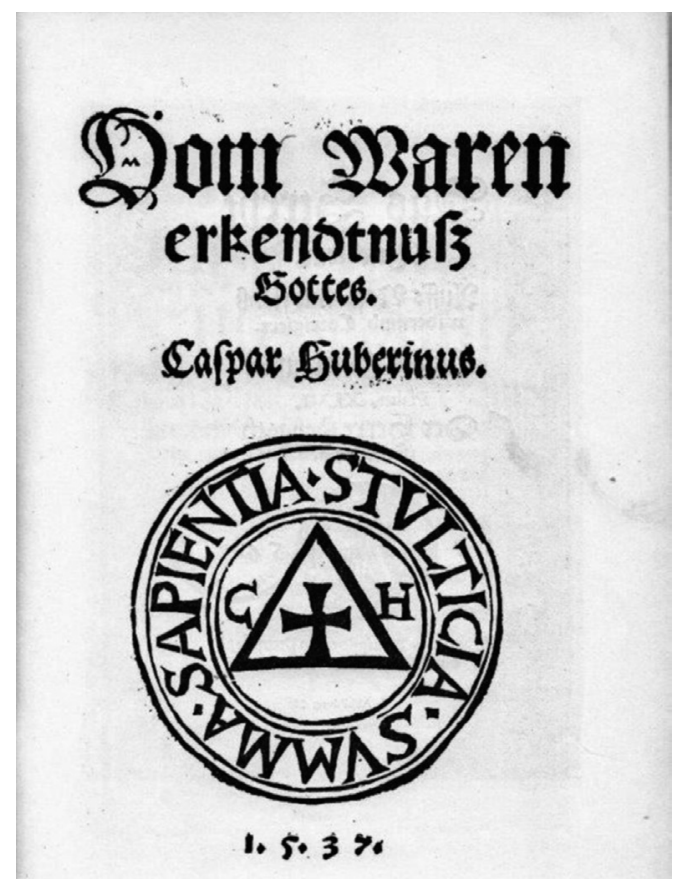

Abb 4: Titelblatt zu Huberinus: Vom Waren erkendtnuß Gottes. Augsburg: Philipp Ulhart 1537. Mit Wappen des Autors. Exemplar der Staats- und Stadtbibliothek Augsburg. Aus Franz: Huberinus - Rhegius - Holbein, Abb. 27.

6. Januar 1544 datierte Vorrede, ist also noch vor dem Fortgang nach Öhringen in Augsburg gedruckt worden. ${ }^{41}$

Wenn Johannes Brenz, der in der Reichsstadt Schwäbisch Hall und im Herzogtum Württemberg wirkte, als „Luthers Mann in Süddeutschland“ bezeichnet wird, ist daneben auch auf Caspar Huberinus in Augsburg hinzuweisen.

\section{Die erste Reformation von Öhringen 1544-1546}

Die Berufung von Huberinus nach Öhringen war schwierig, weil die Grafen von Hohenlohe vor einer reichsrechtlichen Regelung noch nicht zu einer Reformation bereit waren. Wahrscheinlich wurde ihm von Stemler und vielleicht auch

41 Franz: Huberinus (wie Anm. 4), S. 54 f.; 171-176; Erstausgabe von Der klaine Catechismus, Augsburg 1544 (Franz, Nr. 17.1) = VD 16 (wie Anm. 4), 16 H 5377 mit Volltext nach einem Exemplar der Bayerischen Staatsbibliothek München. 
Bräunlein die Aussicht auf eine baldige Reformation der Grafschaft zu optimistisch dargestellt. In Schreiben an Stemler vom 12. Januar und 3. April 1544 gab Huberinus seiner Freude Ausdruck, dass die Grafen so wie er die zwinglianische, schwenckfeldische und andere aufrührerische Lehre verabscheuen. Den Altgläubigen in Hohenlohe wollte Huberinus dem gegenüber mit Milde begegnen: Ich wolle den handel Gottes mit solcher bescheidenheit verrichten, dass auch die widersacher im grund nicht zu klagen hetten, dann ich weiß mit Gottes hülf die schwachen zu dulten, tragen und führen [...]. Im April $1544 \mathrm{kam} \mathrm{Hu}-$ berinus für neun Tage nach Öhringen, selbdritt mit Frau und Tochter ${ }^{42}$. Die acht Artikel, die ihm vorgelegt wurden, begannen: 1. Das er das rein, ware wort Gottes, dem armen volk zu erbauhung des rechten, waren glaubens, auch christenlicher lieb und eusserlicher zucht furtragen. 2. Und dann der zerimonien halber dermassen fasen solt, das die in ierem ersten ursprung in der kirchen mit Gottes gevallen möchten erhalten werden, damit das volk demnacht dardurch zu andacht gezogen und nicht hernider gerissen $[\ldots] .{ }^{43}$

Huberinus teilte beim Einstellungsgespräch seine Absicht mit, eine Predigtreihe über das Buch Jesus Sirach (Ecclesiasticus) zu halten, um die Untertanen zum Gehorsam gegen die Obrigkeit und besonders die Hausväter, das Gesinde und die Jugend zur Zucht anzuhalten. Als Grundlage für die evangelische Ethik diente die jüdische Weisheitsliteratur, die Luther zu den Apokryphen rechnete, weil sie in der griechischen Septuaginta überliefert wurde. 1553 erschienen die Predigten unter dem Titel Spiegel der Haustzucht, Ihesus Syrach genant als stattlicher Foliant mit 374 Blättern, der 18 deutsche und erstaunlicherweise vier tschechische Ausgaben erreichte. ${ }^{44}$

Die Messe wurde in der Öhringer Stiftskirche beibehalten und das Abendmahl unter beiderlei Gestalt zunächst nicht gestattet. 1545 veröffentlichte deswegen Huberinus in Augsburg 70 Thesen - Sibendtzig Schlußred, das beide teil des Sacraments allen gleubigen Christen gereichet soll werden. ${ }^{45}$ Er hatte ehrenhafte Rufe in das Herzogtum Württemberg an die Stuttgarter Stiftskirche als Nachfolger von Erhard Schnepf (1495-1559) und in die Reichsstädte Nördlingen und Rothenburg ob der Tauber erhalten und konnte den Grafen ein Ultimatum stellen. Sie genehmigten am 20. Juni 1546 die Reformation des Gottesdienstes und der Lateinschule in Öhringen. Johann Ruthenus († 1565), der in Wittenberg studiert hatte und in Sachsen und Augsburg Schulmeister war, wurde als Leiter der Lateinschule berufen. ${ }^{46}$ Er hatte mit den Schülern den Gottesdienst in der Stifts-

42 Sehling/Franz (wie Anm. 2), S. 23.

43 Ebd., S. $24 \mathrm{f}$.

44 Franz: Huberinus (wie Anm. 4), S. 58 ff., 196-205; Erstausgabe VD 16 (wie Anm. 4), B 4084 und B 4085. Volltext nach Exemplar der Univ.- und Landesbibliothek Halle.

45 Ebd., S. 56, 176 f; VD 16 (wie Anm. 4), H 5416; Volltext nach Exemplar der Österreichischen Nationalbibliothek Wien.

46 Haug/Cramer/Holtzmann (wie Anm. 18), Nr. 2198. 
kirche musikalisch zu begleiten. Man sang Lieder von Martin Luther aus seinem Gesangbuch: Geistliche Lieder, aufs neu gebessert und gemehrt, zu Wittemberg. Nachdem er sofort 1546 den Entwurf einer Schulordnung eingereicht hatte, verfasste Ruthenus 1549 Eine ordnung, wie es in der schuell zue Öringen gehalten möchte werden. ${ }^{47}$ Morgens und abends zusammen sollte der ganze Katechismus von Johannes Brenz „zur Erbauung“ aufgesagt werden neben Morgen- und Abendsegen und den von Ruthenus gefertigten Chorälen. Ruthenus weigerte sich, mit den Schülern zum Chorgebet der Stiftsherren zu singen, wurde aber an Vespergottesdiensten vor Feiertagen sowie an Sonn- und Feiertagen dazu verpflichtet. Da die Reformation in Öhringen und Hohenlohe stufenweise eingeführt wurde, kann man 1546 als 2. Stufe bezeichnen.

Es gelang nicht, einen von den Grafen bewilligten zweiten Pfarrer für Öhringen zu gewinnen, sodass Huberinus auf Hilfe einzelner Pfarrer aus der Nachbarschaft angewiesen war. Dennoch fand er in Öhringen Zeit, eine Trostschrift Vom christlichen Ritter. Ein wunderbarlicher Kampf der höllischen Bestien wider einen evangelischen Christen ${ }^{48}$ zu verfassen und umfangreiche Predigtsammlungen für den Druck zu bearbeiten, sodass wir eine fast vollständige Dokumentation seiner Predigttätigkeit in Öhringen haben. Die dicken Bände haben trotz des Preises ein erstaunliches Interesse bei Theologen und Laien gefunden.

\section{Das Interim in Augsburg und Hohenlohe}

Nach dem Sieg Kaiser Karls V. über den lutherischen Schmalkaldischen Bund wurde am 30. Juni 1548 in Augsburg das Interim als Zwischenlösung der Konfessionsfrage zum Reichsgesetz erhoben. Es bedeutete für die Protestanten die weitgehende Rückkehr zu den alten Zeremonien, war aber für die katholischen Territorien nicht von Belang. Das unter Waffengewalt erzwungene Interim stieß in evangelischen Territorien wie dem Herzogtum Württemberg oder den Reichsstädten Augsburg und Schwäbisch Hall auf entschiedene Ablehnung und führte zur Entlassung der Geistlichen. In der Herrschaft Hohenlohe-Weikersheim wurde das Interim durch Dekret vom 1. Dezember 1548 eingeführt und die evangelischen Pfarrer in Weikersheim, Schäftersheim, Elpersheim und Nassau entlassen. In Öhringen aber brauchte man nichts zu ändern, da die Messe und die alten Zeremonien noch in Brauch waren. Huberinus verteidigte in zwölf Thesen (die nicht im Druck erhalten sind) die Annahme des Interims, da das Abendmahl mit Brot und Wein, evangelische Predigt, evangelischer Glaube und die Priesterehe freigegeben seien. ${ }^{49}$ Der gelehrte Matthias Flacius (Vlacich, nach seiner Heimat

47 Sehling/Franz (wie Anm. 2), S. 28 ff.

48 Franz: Huberinus (wie Anm. 4), S. 56, 177-184.

49 Fridericus Jacobus Beyschlag: Sylloge variorum opusculorum. T.1. Halae Suevorum 1729, S. 554-557 (nach einer nicht eigenhändigen Handschrift); Wibel (wie Anm. 8), 3, Codex Diplomaticus S. $343 \mathrm{ff}$. 
Illyricus genannt, 1520-1575) veröffentlichte eine Streitschrift gegen Huberinus. ${ }^{50}$ Flacius lehnte es ab, dass es Adiaphora, nicht glaubensentscheidende Zeremonien, die man zugestehen könne, gäbe. In Magdeburg verfasste Flacius auch verschiedene Streitschriften gegen Philipp Melanchthon und dessen Schüler (adiaphoristischer Streit). Wegen verschiedener anderer Streitigkeiten wurden Flacius und seine Anhänger schließlich vertrieben und verfolgt. Die Polemik des Flacius hätte Huberinus also nicht besonders treffen müssen. Nach dem Tod des Reformators Martin Luther 1546 fehlte die maßgebliche Autorität. Heute kann man Caspar Huberinus in seinem Bemühen um eine gemäßigte Reform des Gottesdienstes, Predigt, Kirchengesang und eine christliche Erziehung der Jugend als Vorläufer der Ökumene anerkennen.

Als Graf Georg I. von Hohenlohe in Waldenburg am 16. März 1551 gestorben war, hielt Huberinus in der Öhringer Stiftskirche die Leichenpredigt, in der er betonte, dass Graf Georg freie öffentliche Predigt des Gotteswortes und 1550 allen Untertanen den Empfang des Abendmahls unter beiderlei Gestalt erlaubt habe, wie er es sich auch selber habe reichen lassen. ${ }^{51}$ Nachdem die Grafen von Hohenlohe in der Religionsfrage die Entscheidung des Kaisers abwarten wollten, diente das Interim, das eigentlich nicht für katholische Gebiete bestimmt war, als Genehmigung für bescheidene Reformen. In einzelnen ritterschaftlichen Gebieten in Franken nördlich von Hohenlohe handelte man ebenso. ${ }^{52}$

Kaiser Karl V. und sein Kanzler Antoine Perrenot de Granvelle, Bischof von Arras (1517-1586), bemühten sich bei Graf Ludwig-Casimir (1517-1568), der im August 1551 in Neuenstein zur Regierung gekommen war (sein Bruder Eberhard, 1535-1570, war noch unmündig), um die Beurlaubung von Huberinus nach Augsburg. Nach jahrelangen Kämpfen gegen zwinglianische Prediger in Augsburg hat es Huberinus gereizt, dass er auf Wunsch des Kaisers in seine Heimatstadt zurückkehren sollte. Er wollte der Bevölkerung durch evangelische Predigt, Lieder und Seelsorge helfen und berichtete, welche Freude beim Weihnachtsgottesdienst geherrscht habe. Von den zwinglianischen Gegnern wurde er aber als Buberinus (Bube $=$ Schurke) und Verräter beschimpft. Die kurze Episode wurde bereits im Frühjahr 1552 beendet, als die evangelischen Fürsten unter Führung von Moritz von Sachsen (1521-1553) in Augsburg einzogen. Nach dem Passauer Vertrag sollte im Reich freie Religionsausübung bis zum nächsten Reichstag, der 1555 in Augsburg abgehalten wurde, gestattet sein.

50 Matthias Flacius: Contra quaedam interimistica \& adiaphoristica scripta. Magdeburg um 1550; Franz:, Huberinus (wie Anm. 4), S. 209; VD 16 (wie Anm. 4), F 1329, Volltext nach Exemplar der Österreichischen Nationalbibliothek Wien.

51 Acta (wie Anm. 12), S. 347-353. Die Grabplatte Graf Georgs I. befindet sich in der Stadtkirche Waldenburg, Drös (wie Anm. 27), Nr. 270.

52 Helmut Neumaier: Reformation und Gegenreformation im Bauland unter besonderer Berücksichtigung der Ritterschaft (FWFr 13). Schwäbisch Hall 1978. 


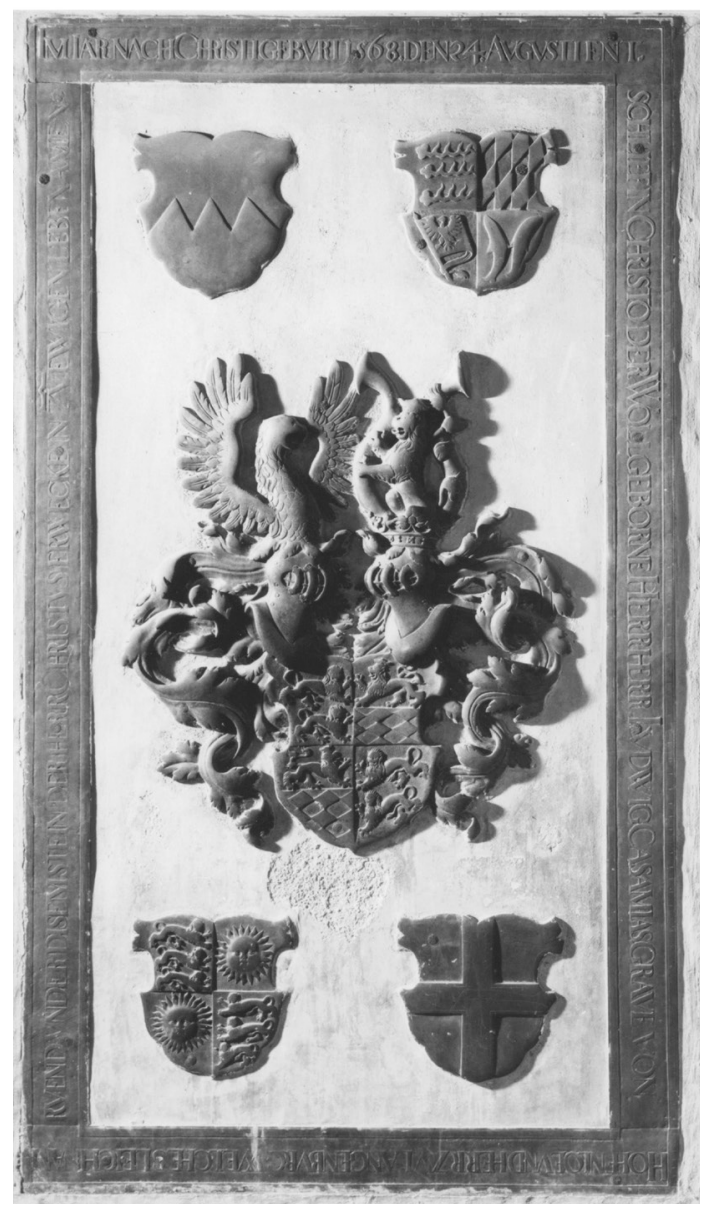

Abb. 5: Grabmal für Graf Ludwig Casimir im Chor der Öhringer Stiftskirche. Foto Harald Drös, DI 73, Nr. 325 Abb. 5-8 Inschriftenkommission der Heidelberger Akademie der Wissenschaften.

\section{Die Kirchenordnung von 1553 und der Tod von Caspar Huberinus}

Huberinus kehrte nach Öhringen zurück und brachte zwei weitere Interimsgeistliche mit, die am 11. Juni 1552 in Augsburg entlassen worden waren. Hieronymus Hertel (Härtel, gest. 1556) erhielt als Pfarrer in der Residenzstadt Neuenstein das zweitwichtigste geistliche Amt in der Grafschaft, Thomas Wiedmann (Widmann, * 1500) wurde Pfarrer in dem zur Reichsstadt Schwäbisch Hall gehörenden Untermünkheim und 1555-1558 in Jungingen. ${ }^{53}$ Der hohenlohische 
Rat Ägidius Stemler in Öhringen hatte wahrscheinlich zusammen mit Huberinus und Hertel den Plan einer gemäßigten Reformation. Er forderte Hertel auf, sein guttbedunken von ceremonien und satzungen der menschen einzureichen. Erhalten ist die handschriftliche Christliche kirchenordnung der graveschaft Hohennloe etc. $1553 .{ }^{54}$ Diese Ordnung kann neben Huberinus auch Hertel zum Autor haben. Es handelt sich um keine Interimsordnung, sondern eine echt lutherische Ordnung, die besonders in der Frage der Gottesdienstsprache und der Ordnung der evangelischen Messe sehr konservativ ist. Benutzt sind die Brandenburg-Nürnbergische Kirchenordnung von 1533 und die Pfalz-Neuburgische Kirchenordnung von 1543. $\mathrm{Zu}$ den württembergischen Kirchenordnungen von 1536 und 1553 besteht ein deutlicher Unterschied. Aus dem Visitationsprotokoll von 1556 lässt sich entnehmen, dass die Kirchenordnung keineswegs in der ganzen Grafschaft Hohenlohe, sondern wahrscheinlich außerhalb Öhringens und Neuensteins nur in den benachbarten Pfarreien und im Amt Ingelfingen gehalten wurde. Wenn man die Genehmigung des Abendmahls unter beiderlei Gestalt 1550 als Zwischenschritt betrachtet, erfolgte mit der Kirchenordnung 1553 die 3. Stufe der Reformation in Hohenlohe.

Huberinus starb am 6. Oktober 1553 an einer Infektion, die er sich bei einem Krankenbesuch geholt hatte. An seinem 50. Geburtstag am 21. Dezember 1550 hatte Huberinus (wegen der früher kürzeren Lebenserwartung) seine Grabschrift verfasst, die er in dem Band Zehenerley Kurtze Form zu Predigen 1552 veröffentlichte.

\section{Ein Grabschrift Caspars Huberini. Ach ein Sünder, Geborn, gelebt, gestorben bin ich. Christe mein Herr, Erneu, vergib, auferwecke mich. Ich bin gläubig, Erhalt, verklär, mache mich selig.}

Das Epitaph mit dieser Grabschrift ist in der Öhringer Friedhofskapelle St. Anna erhalten. ${ }^{55}$

Der Sohn David Huberinus (1540-1598) wurde Domprediger in Verden an der Aller, nahm an der Visitation zur Einführung der Reformation im Stift Verden teil und wurde der erste evangelische Superintendent.

54 Sehling/Franz (wie Anm. 2), S. 53-81.

55 Ab 1555 gedruckt unter dem Titel Mancherley Form zu predigen (siehe Anm. 4); Franz: Huberinus (wie Anm. 4), S. 57 f., 193-196; VD 16 (wie Anm. 4), H 5624 mit Volltext nach Exemplar der Bayerischen Staatsbibliothek München; Franz, Grabschrift und Wappen (wie Anm. 40). Siehe den Schluss dieses Beitrags. 


\section{Die Reformation von 1556}

Am 25. September 1555 wurde in Augsburg der Religionsfrieden als Reichsgesetz verkündet. Weltliche Herrschaften und auch die reichsunmittelbare Ritterschaft, die in der Nachbarschaft der Grafschaft Hohenlohe viele Dörfer besaß, konnte die Konfession der Untertanen bestimmen. Durch den Religionsfrieden wurde das Nebeneinander von Katholiken und Lutheranern im Deutschen Reich ermöglicht, zugleich aber auch die Spaltung verewigt. In Hohenlohe gab es in dieser Zeit einen großen Erbschaftsstreit. Nach dem Tod Graf Georgs hatte Graf Ludwig Casimir Auseinandersetzungen mit seiner Stiefmutter Helene Truchsessin von Waldburg (gest. 1567) und ihren unmündigen Kindern (Ludwig Casimirs Halbgeschwistern) Eberhard (1535-1570) und Georg II. (1544-1554). 1553 bis 1555 erfolgte die Hauptlandesteilung mit den bis heute bestehenden Familienzweigen Neuenstein und Waldenburg. Die Hauptstadt Öhringen mit dem Spital und der Vogtei über das Stift blieb - wie bereits 1511 als Hausgesetz vereinbart worden war - gemeinschaftlich. Herzog Christoph von Württemberg (15151568) schlichtete als kaiserlicher Kommissär vom 17. bis 20. Juni 1555 den Rechtsstreit, sprach bei dieser Gelegenheit die Durchführung der Reformation an und sagte seine Unterstützung zu.

Herzog Christoph ließ Johann Hartmann († 1575), Pfarrer in Güglingen bei Heilbronn, auffordern, ein Jahr lang nach Öhringen zu gehen, damit die Eer Gottes sovil müglich allenthalben erweytert und gepflanzet werde. Nach Ablauf der einjährigen Beurlaubung wurde Hartmann auf Gesuch von Graf Ludwig Casimir als Stiftsprediger Generalsuperintendent, also führender Geistlicher der gesamten Grafschaft. Johann Hartmann holte im September 1556 seinen Bruder Gallus Hartmann, der Pfarrer in der Reichsstadt Esslingen war, als Stadtpfarrer und Hofprediger in die Residenzstadt Neuenstein. (Sein Grabmal ist im Chor der Neuensteiner Kirche erhalten.) ${ }^{56}$

Außerdem wurde David Büttner oder Püttner, der sich nach Humanistenart Pythonius nannte $(\uparrow 1572)$, für ein Jahr von Nürnberg nach Hohenlohe geholt, um bei der Reformation zu helfen. Er war Diaconus an St. Sebald in der Reichsstadt Nürnberg, eine angesehene Stellung. Er zog nach Weikersheim, wurde auch in Öhringen und in Neuenstein bei Hof benötigt, musste aber bereits am 3. Februar 1557 den Dienst quittieren. ${ }^{57}$ In seiner Bestallung ist der Satz wichtig, dass Püttner 10 Gulden erhielt, um dem Grafen dafür 30 stethisch Ordnung zu senden. Gemeint war die gedruckte Kirchenordnung der Reichsstadt Nürnberg, die 1533 zusammen mit der benachbarten Markgrafschaft Brandenburg (Ansbach und Bayreuth) erlassen worden war. So wirkten die Einflüsse von zwei großen evangelischen Gebieten zusammen, Württemberg von Süden und Brandenburg-Nürn-

56 Haug/Cramer/Holtzmann (wie Anm. 18), Nr. 878 und 874; Franz: Kirchenleitung (wie Anm. 2), Register; Drös (wie Anm. 27), Nr. 423.

57 Sehling/Franz (wie Anm. 2), S. 88-90; Haug/Cramer/Holtzmann (wie Anm. 18), Nr. 1999. 
berg von Osten. Für den Gottesdienst wurde aber die liturgisch reichere Brandenburg-Nürnbergische Ordnung eingeführt, die in der Hohenlohischen Kirchenordnung von 1578 weitergeführt wurde und bis Anfang des 19. Jahrhunderts den Gottesdienst in Hohenlohe von Württemberg unterschied.

Sofort nach der Ankunft Johann Hartmanns wurde die Reformation des Öhringer Stifts in Angriff genommen. ${ }^{58}$ Am 4. Februar 1556 trafen sich Räte und andere Beamte in Öhringen zur Beratung gemeinsamer Fragen. Obwohl die Grafen von Hohenlohe als Schirmherren bereits 1343 versprochen hatten, den Besitz des Stiftes für alle Zeiten unangetastet zu lassen, haben sie bereits vor der Reformation über die Einkünfte verfügt und verdienten Beamten Pfründen, Gehaltszulagen oder Stipendien zum Studium ihrer Söhne verliehen. Auch im Vergleich mit anderen Territorien war es positiv, dass man sich 1556 auf Ausgaben für gemeinsame Kirchen- und Schulsachen beschränkte: die vier Öhringer Geistlichen, das Gymnasium und Stipendien für den Besuch von höheren Schulen und Universitäten. Alle Pfarrer der Grafschaft wurden von Graf Ludwig Casimir auf Pfingstmontag, den 25. Mai 1556, nach Öhringen zusammengerufen, da ihnen am nächsten Tag (26. Mai) eine Mitteilung gemacht würde, deren Inhalt vorher nicht mitgeteilt wurde. ${ }^{59}$ Ein Pfarrer notierte im Kalender: Anno Domini 1556 haben die wolgebornen Herrn von Hohenloe etc. alle ire Pfarher beschrieben und sie gen Oringen bescheiden, inen angezeigt, eine newe Refermation zu machen, das Meßopfer abrogirt, ubi multi adfuerunt. Das ist den 25. May geschen. Den Pfarrern wurde der Befehl gegeben, in Kürze (ab dem 9. Juni) zusammen mit den Schultheißen, Gemeindevertretern und Schulmeistern zum Examen und zur Inquisition (Befragung) erneut nach Öhringen zu kommen. Statt einer Visitation in den Gemeinden handelte es sich um eine Befragung in der zentralen Stadt. Die Fragen behandelten die Personalien des Pfarrers, seine Lehre und Amtsführung. 4. wurden die Kirchen- und Schuldiener gefragt, ob sie gebührlichen Unterhalt haben und Pfarr- und Schulhaus im Stand seien. 5. wurde der Lebenswandel der Gemeindeglieder erforscht. Es wurde gefragt, ob sie Predigt und Abendmahl fleißig besuchen und den Pfarrer ehrfürchtig behandeln, ob sie in öffentlichen Sünden und Lastern leben und ob Streit zwischen Eheleuten oder Eltern und Kindern bestände. Und wenn schon nach Wucherern, Gotteslästerern und Wiedertäufern geforscht werden musste, fügt sich eine Frage, ob nicht aufrürische Leut und die lesterlich von der Obrigkeit reden, seyen zwanglos an. Auf die Frage, ob noch Wallfahrten und andere gräuliche Abgöttereyen geübt werden, wurde eine Fülle alter Bräuche berichtet. Die letzten Fragen bezogen sich auf die Instandhaltung der Friedhöfe, die Versorgung der Armen und den Zustand der Schulen.

58 Sehling/Franz (wie Anm. 2), S. 97-104; Franz: Reformation in Öhringen (wie Anm. 17), S. $113 \mathrm{ff}$.

59 Gustav Bossert: Die Akten der General-Kirchenvisitation der Grafschaft Hohenlohe vom Jahr 1556. In: WVjH 3 (1880), S. 173-212, 253-280; Franz: Kirchenleitung (wie Anm. 2), S. 16-27; Sehling/Franz (wie Anm. 2), S. 93-96. 
Es handelte sich um eine umfassende Bestandsaufnahme. In einem Bericht von 1584 heißt es, dass die Grafen Ludwig Casimir und Eberhard (der noch nicht mündig war) in der gantzen Graffschaft Hohenlohe und in allen iren Kirchen, Clostern, Pfarhern und Filialn die bepstliche Lehr gantz und gar ausgemustert und die Lehr des heiligen Evangelii nach Augsburgischer Confession sambt den Kirchenceremonien auch angerichtet hätten.

Bei der Befragung in Öhringen wurde den Pfarrern die Brandenburg-Nürnbergische Kirchenordnung übergeben. Da sie nicht alle Fragen behandelte, wurde zur Ergänzung eine nicht erhaltene handschriftliche hohenlohische Ordnung, unser gnedigen herren kirchenordnung, erstellt. Zwei Jahre nach der Befragung in Öhringen wurde 1558 eine Generalvisitation in allen Gemeinden durchgeführt. Erhalten ist die Ordnung für Hohenlohe-Waldenburg. ${ }^{60}$ Als Motto diente das Wort des Apostels Paulus im 1. Korintherbrief $(14,40)$ : Lassents alles zuchtiglich und ordenlich zhughen, das man häufig als Begründung für Kirchenordnungen anführte. Wichtig ist der Abschnitt Von der Oberkait als Beschützerin der Kirchen. Im Unterricht der kursächsischen Visitatoren 1528 wollte Martin Luther, dass der Kurfürst um der Liebe Amt, als „Notbischof“ sich der Kirche annehme, da die eigentlichen Bischöfe ihr Amt nicht richtig wahrnehmen. In der hohenlohischen Ordnung heißt es: Die Oberkait soll ermant und gepotten sein, das sie sich der Kirchen und Visitation mit Ernst anemme, dann sie ist solches zu tun schuldigt. Beispielsweise werden im 5. Buch Mose (Deuteronomium) 17, 19 die Könige ermahnt, dass sie nicht allein selbst Gottes Wort lesen, sondern auch dasselbige bei den Untertanen pflanzen und erhalten. Neben dem Vorbild der alttestamentlichen Könige werden die christlichen Kaiser genannt: Constantinus, Theodosius und andere haben sich auch der Kirchen und Gottesdiensts angenommen. Die Lehre von der Pflicht der Obrigkeit, für die Kirche zu sorgen, war in Oberdeutschland verbreitet und wurde vor allem von Johannes Brenz vertreten.

Mit der Visitation von 1558 war die Einführung der Reformation in der ganzen Grafschaft zum Abschluss gekommen. In den fast zwanzig Jahren bis zum Tode des Superintendenten Johann Hartmann im Jahr 1575 konnte sich die Reformation in Hohenlohe in Ruhe festigen. Die Pfarrer hatten eine relativ große Freiheit. Nur 1571 ist eine Visitation in der Neuensteiner Hälfte der Grafschaft bezeugt, deren ausführliches Protokoll die Fortschritte zeigt. ${ }^{61}$ Die Grafschaft Hohenlohe war eine Insel der Ruhe und des Friedens in dem von Lehrstreitigkeiten zerrissenen Deutschland. Johann Hartmanns Öhringer Kollegen schrieben nach seinem Tod, dass die Kirchen dieser Landsart [...] bisher one Ruhm zu melten in der Lehr und Ceremonien ganz fridlich und eintrechtig gewesen. Trotzdem waren die zwei Jahrzehnte von 1556 bis 1575 durch ihre „Unordnung“

60 Franz: Kirchenleitung (wie Anm. 2), S. 38-47; Sehling/Franz (wie Anm. 2), S. 116-133.

61 Gustav Bossert: Die kirchlichen Zustände der Grafschaft Hohenlohe-Neuenstein im Jahre 1571. In: BWKG, NF 30 (1926), S. 2-42; Franz, Kirchenleitung (wie Anm. 2), S. 63-74; Sehling/Franz (wie Anm. 2), S. 159-170. 
gekennzeichnet. Weder wurde die Kirchenordnung oder der Katechismus überall in der Grafschaft gleich gehalten, noch gab es genaue Vorschriften für die Übung der Kirchenzucht und der Kirchenleitung. ${ }^{62}$ Dem sollte durch die 1578 gedruckte Kirchenordnung und eine umfassende Neuordnung des Kirchenwesens in Verbindung mit Polizeiordnungen und dem Ausbau des Landrechts abgeholfen werden. Graf Wolfgang II. (1546-1610, reg. ab 1574) nutzte in den Jahren 1576 bis 1583 die Gelegenheit als Waldenburger Mitvormund zum Erlass gemeinsamer Ordnungen für die Gesamtgrafschaft. ${ }^{63}$

\section{Epilog: Grabmäler in der Öhringer Friedhofskirche}

In der Öhringer Friedhofskapelle St. Anna findet man neben dem Epitaph für Caspar Huberinus das Grabmal für Johann Hartmann, das ihn als Prediger auf der Kanzel der Stiftskirche zeigt.

Das Grabmal für Huberinus hat das Format einer Grabplatte, befand sich aber im 18. Jahrhundert bereits an der jetzigen Stelle an der Wand. Das Wappen in der Mitte, das sich auch auf den Titelblättern des Buches Von der wahren Erkenntnis Gottes 1537 und anderer Schriften findet, ${ }^{64}$ wurde erweitert durch eine Krone mit den Buchstaben I R (Iesus Rex). Zusammen mit den Buchstaben MH kann man Christe mein Herr lesen. Die folgenden Buchstaben $H B$ werden den Steinmetz bezeichnen, vielleicht Hans Bruckner, den Meister des Stiftsamtshauses von $1554{ }^{65}$ Der Stiftsprediger und Superintendent Johann Hartmann starb am 20. September 1575 und erhielt ein ebenso hohes Epitaph wie Huberinus $(169 \mathrm{~cm})$ im Chor der St. Annen-Kirche. ${ }^{66}$ Sein Wappen zeigt einen runden Turm mit Zinnen, darauf einen bärtigen Mann, in beiden erhobenen Händen je eine Kugel haltend. Es ist wohl ein redendes Wappen (Mann auf dem Turm = starker Mann = Hartmann). Bei dem Relief ist interessant, dass alle Gottesdienstbesucher Kopfbedeckungen tragen. Die Frauen sitzen getrennt in der letzten Reihe und tragen einen Schleier um das Kinn. Dass dies ein fester Brauch war, geht daraus hervor, dass 1592 als „Hexen“ angeklagte Frauen bei Androhung oder unter dem Zwang der Folter ausgesagt haben, der Teufel habe sie verpflichtet, beim Empfang des Abendmahls die Hostie in den Schleier fallen zu lassen und ihm zu überbringen (damit der Teufel Hostienfrevel begehen kann). Deswegen wurde das Verschleiern der Frauen beim Abendmahl verboten! ${ }^{67}$

62 Franz: Kirchenleitung (wie Anm. 2), S. 74.

63 Sehling/Franz (wie Anm. 2), S. 16f., 226-518.

64 Drös (wie Anm. 27), Nr. 276; siehe bei Anm. 40.

65 Eberhard Knoblauch: Die Baugeschichte der Stadt Öhringen vom Ausgang des Mittelalters bis zum 19. Jahrhundert. Textbd. 1. Stuttgart 1991, S. 303.

66 Drös (wie Anm. 27), Nr. 365.

67 Sehling/Franz (wie Anm. 2), S. 627. 


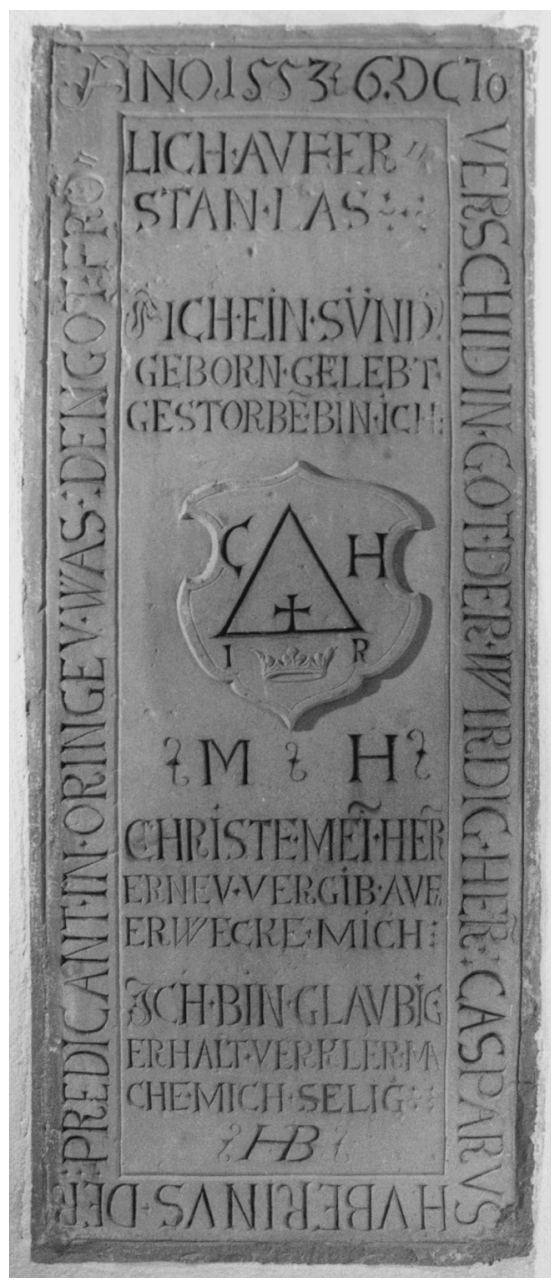

Abb. 6: Grabplatte oder Epitaph für Caspar Huberinus in der Öhringer St. Anna-Kirche 1553. Foto Harald Drös, DI 73, Nr. 276.

Darunter findet sich ein lateinisches Grabgedicht in Distichen, verfasst von dem Rektor der Öhringer Lateinschule, Karl Christoph Baier (Beyer, 1527 - nach 1590, in Öhringen 1567-1582). ${ }^{68}$ Darin heißt es: [...] qui superintendentis onus cum laude gerebat / primus et e templis expulit usque papam. (er, der als erster die schwierige Aufgabe des Superintendenten lobenswert erfüllte und der allenthalben den Papst aus den Kirchen verjagte).

68 Ebd., S. 47 und Register; Haug/Cramer/Holtzmann (wie Anm. 18), Nr. 89. 


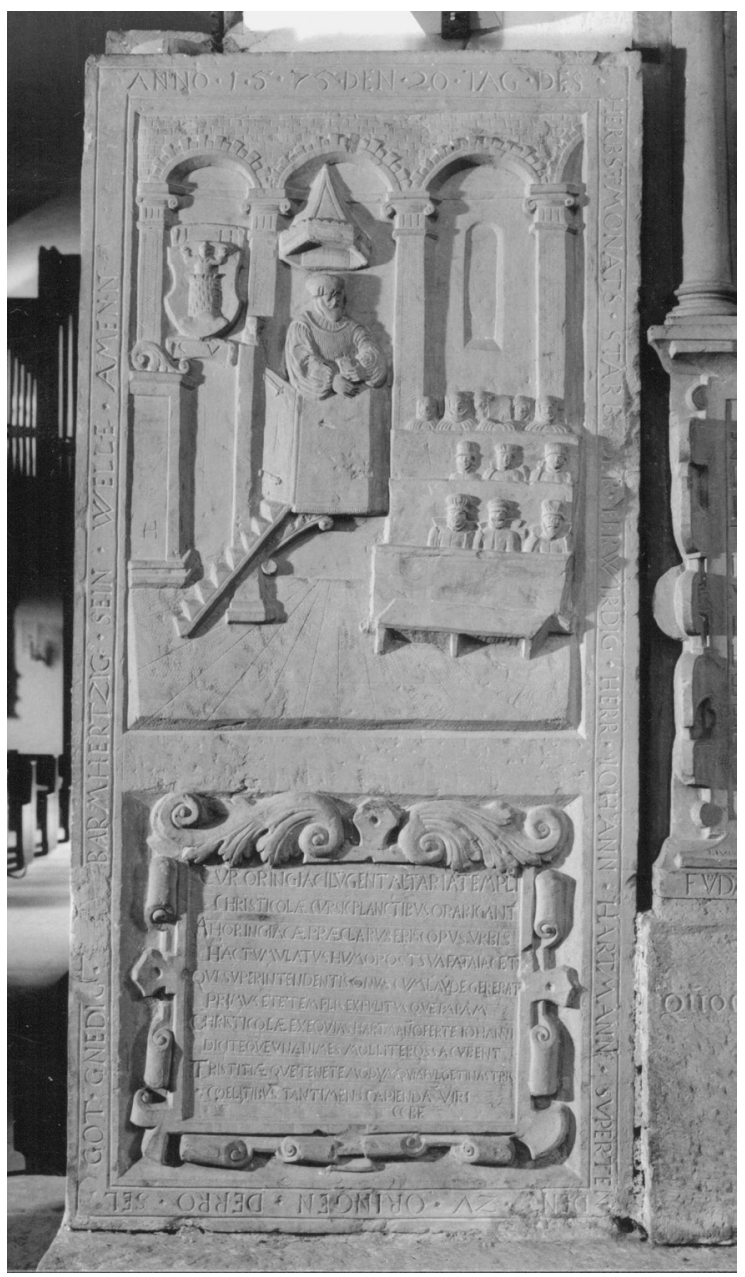

Abb. 7: Epitaph für den Stiftsprediger und Superintendenten Johann Hartmann in der Öhringer St. Anna-Kirche 1575. Foto Harald Drös, DI 73, nr. 365.

Im Boden des Chors der Friedhofskirche liegt die Grabplatte der Dorothea Meier, des Hans Hartmans bred(igers) hausfraw, mitsamt ihren vier Kindern Abraham, Dorothea, Magdalena und Maria ${ }^{69}$ Die Formulierung ist nicht ganz eindeutig; die Kinder scheinen am selben Tag wie die Mutter, am Heiligabend 1556 verstorben zu sein. War es ein schreckliches Unglück wie ein Brand oder eine Krankheit? Man hätte auch in anderen Quellen davon erfahren müssen. So ist im Pfarrerbuch Württembergisch-Franken nur eine frühere Ehefrau Magdalene (ge- 
heiratet vor 9. 1527) bekannt. Johann Hartmann war 1556 von Herzog Christoph von Württemberg für ein Jahr als Prediger nach Öhringen beurlaubt worden. Trotz des Todes seiner gesamten Familie ist er in Hohenlohe geblieben, wurde am 12. Februar 1557 aus dem württembergischen Dienst entlassen und anschließend zum Superintendenten ernannt.

Caspar Huberinus und Johann Hartmann hatten hinsichtlich des Interims gegensätzliche Auffassungen und Biographien. Für beide Theologen war aber die Predigt des Evangeliums ein zentrales Anliegen. Sie haben die stufenweise Einführung der Reformation in den dramatischen Jahren von 1544 bis 1556/1558 begleitet und gestaltet. ${ }^{70}$

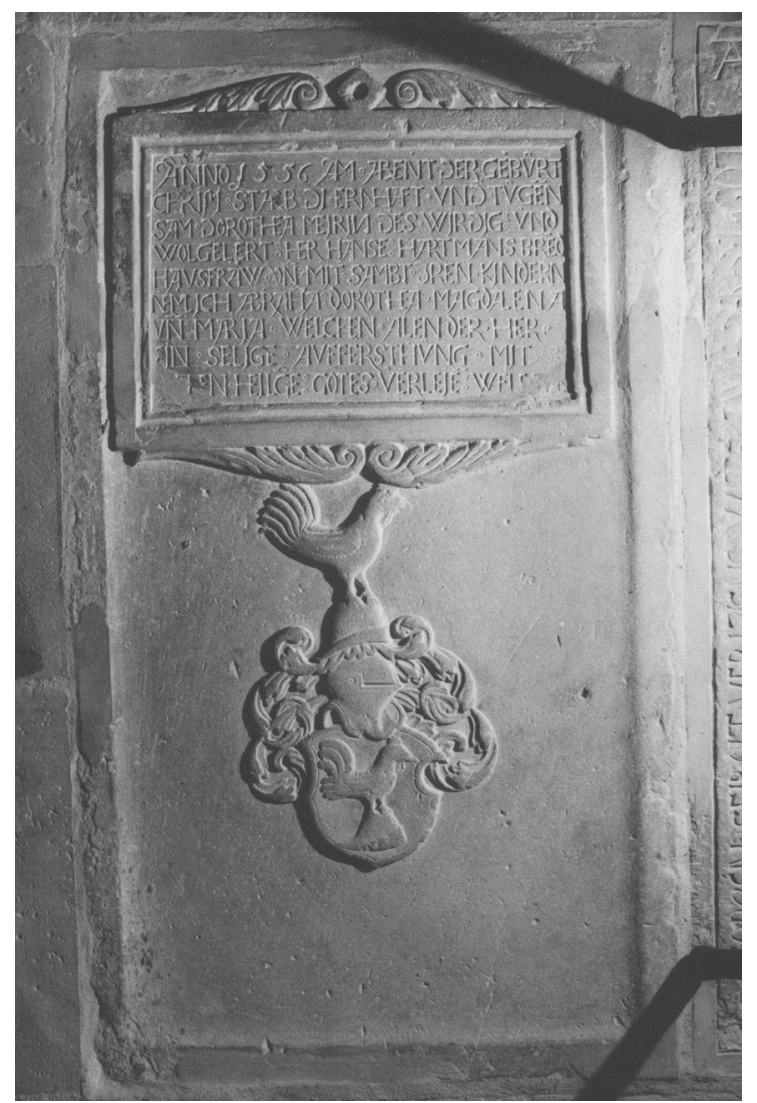

Abb 8: Grabplatte für Dorothea Mei(e)r, verheiratete Hartmann in der Öhringer St. Anna-Kirche 1556. Foto Harald Drös, DI 73, Nr. 289. 